\title{
Assessment Institute Insights A Report of the STEM Education Track of the 2017 Assessment Institute
}

Anthony Chase

2017 marked the return of the STEM Education track to the Assessment Institute. This track began its re-entrance into the institute by a keynote address to a packed room by Ann Austin entitled "Addressing Key Issues Relevant to Designing Effective Evaluation." Austin's keynote engaged many faculty and researchers about an issue that is central to the STEM educational research process: evaluation. She drew upon her experiences at the National Science Foundation as a program officer to explain the importance of evalu- these was "An Overview of MixedMethods Research Approaches" by Justin Hess of the STEM Education Innovation and Research Institute at IUPUI. In his talk, Hess emphasized some of the key theoretical approaches and practical applications of mixed-methods research in education. He helped make the distinction between qualitative theory and quantitative methods, as well as where they converge. A second fundamental session that was presented at this year's institute was "Beyond Anecdotes: Making Use of

This track provided not only a solid foundation of the fundamentals of STEM educational research, but gave an insight into some examples of current assessment research in the field. These ranged from the quantitative methods such as instrument development, reliability testing, and validation to qualitative methods such as interviews, focus groups, and observations. ๑ా

ation in grant proposals. This includes the potential pitfalls that spurred a great discussion afterward about common issues that come up when reviewers look at evaluation sections of grant proposals. She also spoke of the crucial differences between evaluation and research, as well as the differences between internal and external evaluators on projects. Participants leaving the session received plenty of information to help equip them to design and implement their own evaluations (including formative and summative assessments, logic models, and theories of change).

Several sessions in this track placed an emphasis on the fundamentals of STEM education research. One of
Qualitative Data in STEM Education Assessment and Evaluation" by Grant Fore, also from the STEM Education Innovation and Research Insitute. Fore explored the potential for qualitative research methods to contribute to the evaluation and assessment of STEM education programming. When used in the assessment and evaluation of educational programming in STEM, qualitative data can aid in the description of (1) how students learned in such programs, (2) the subtle effects of the teacher/student relationship, and (3) the nuanced ways through which students come to inhabit STEM identities, to name a few. We were shown through this session that while quantitative data may reveal generalizable patterns, the strength of qualitative data is in its capacity to contribute to descriptions of how and why such patterns may come to be and how they are locally experienced.

These fundamental pieces equipped participants not just with information regarding the types of educational research in STEM, but the specific practices and theoretical frameworks by which they are performed. These fundamental components of the track set the foundations for other applied sessions that demonstrated the impact and methods of specific STEM educational research projects. This was kicked off by Carolyn S. Gentle-Genitty, Natasha Bragg, Jangmin Kim, and Eun-Hye Yi from the Indiana University School of Social Work with their talk, "Evaluating for Student Success: Student Bonds = Student Success." As the key presenter, Gentle-Genitty described in detail how her team was able to link student bonding to success measures in the classroom. She first introduced the three components of school bonding: attachment, involvement, and belief/commitment. She then linked these to her measurement instrument and showed the validation/reliability testing for it. Using this instrument, she then examined the bonds made by students as well as how these bonds were split up by demographic information such as race and gender. With her novel insights into generational differences of the current student population and effective methods for reaching and engaging them, she provided institute participants with helpful strategies to implement in their own universities and classrooms. 
Another presentation was "Research Findings from a System-Wide STEM Service-Learning Study" by Judy Botelho and Cathy Avila-Linn from California State University in partnership with Rebecca Eddy and Nicole Galport from Cobblestone Applied Research \& Evaluation Inc. in California. Ollivettee Hill and Victor Agbasi of El Centro College presented "Designing Effective Assignments and Signature Work in Chemistry," in which they shared the process of developing their assessment, how the assessment was implemented, and the initial results of this assessment. The description of process was very useful, as it gave the session participants the ability to see the progression of instrument development and piloting within a chemistry course.

This track also incorporated a session presented by Dominique Galli, director of the Center for Research and Learning at IUPUI, entitled "Assessing Student Learning in Undergraduate STEM Research Using the Principles of Undergraduate Learning." Five of
IUPUI's Prinicples of Undergraduate Learning (communication, critical thinking, application of knowledge, intellectual depth, and ethics) were applied to a research environment. Further, Galli presented a description of activities that align faculty-mentored independent STEM research with undergraduate student learning, an outline of an assessment strategy, and a presentation of the data that has been collected using this strategy. Participants in this session not only gained the ability to better assess activities in undergraduate STEM research programs, but learned from this project how to better monitor the mentor engagement with undergraduate students. Galli noted that many universities contain large guiding principles such as these, but little has been done to show how practically one might use these to engage students.

This track provided not only a solid foundation of the fundamentals of STEM educational research, but gave an insight into some examples of current assessment research in the field.
These ranged from the quantitative methods such as instrument development, reliability testing, and validation to qualitative methods such as interviews, focus groups, and observations. Sessions in this track further showed how to merge these methods into robust mixed-methods projects that utilize multiple data sources. Presentations of current work showed the extensions of STEM educational research into the university policies as well as how to navigate a changing undergraduate student body and modify teaching methods in which to best engage them. Moving forward, this track will seek out research that focuses on the development of interventions, development of assessment instruments, validation of instruments, and generalizability of interventions throughout the wide breadth of courses in the STEM fields.

\section{Anthony Chase is an evaluation and research specialist in the STEM Education Innovation and Research Institute at IUPUI.}

NOTE: Assessment Institute Insights is a column featuring ideas, content, and resources from the Assessment Institute in Indianapolis. Now the nation's oldest and largest event focused exclusively on outcomes assessment in higher education, the Assessment Institute attracts some 1,000 participants from nearly all 50 states and several foreign countries. The institute features special tracks in assessment related to community engagement, ePortfolios, faculty development, global learning, graduate/graduate professional education, high-impact practices, learning improvement and innovation, NILOA, STEM education, and student affairs programs and services. This year's institute will be held October 21-23, 2018, at the Indianapolis Marriott Downtown. More information about the Assessment Institute may be found at http://assessmentinstitute.iupui.edu/.

\section{Future Dates for Assessment Institute in Indianapolis}

(Note: All Institute events will be held at the Indianapolis Marriot Downtown Hotel, 350 West Maryland Street, Indianapolis, Indiana.)

2018 Assessment Institute in Indianapolis

Pre-Institute Workshops: October 21, 2018

Institute Dates: October 22-23, 2018

2019 Assessment Institute in Indianapolis

Pre-Institute Workshops: October 13, 2019

Institute Dates: October 14-15, 2019
2020 Assessment Institute in Indianapolis

Pre-Institute Workshops: October 25, 2020

Institute Dates: October 26-27, 2020

2021 Assessment Institute in Indianapolis

Pre-Institute Workshops: October 24, 2021

Institute Dates: October 25-26, 2021 
Copyright of Assessment Update is the property of John Wiley \& Sons, Inc. and its content may not be copied or emailed to multiple sites or posted to a listserv without the copyright holder's express written permission. However, users may print, download, or email articles for individual use. 